\title{
The Effect of Tree Plantations on Moderating Air Temperature in Arafat, Makkah for the Period 2002-2016
}

\author{
Said Munir, Turki M. Habeebullah, Esam A. Morsy and Atef M.F. Mohammed \\ The Custodian of the Two Holy Mosques Institute for Hajj and Umrah Research, Umm Al-Qura \\ University, Makkah, Saudi Arabia
}

\begin{abstract}
Recently many studies have shown that average temperature has increased globally. However, temperature trends vary in different parts of the world due to local geographical, climatic, land usage and various socio-economic factors. This study focuses on temperature trend in Makkah and intends to investigate the effect of vegetations on temperature trend. Temperature trend is analyzed from two meteorological monitoring sties in Arafat and Waly Al-Ahd area for the period 2002-2016. The two sites have demonstrated opposite trends from each other for the above period. In Arafat area temperature has not increased and has rather decreased during the last 15 years $\left(-0.05^{\circ} \mathrm{C} /\right.$ year $)$. The negative trend in Arafat was more evident since $2009\left(-0.21^{\circ} \mathrm{C}\right.$ year). In contrast, Waly Al-Ahd area demonstrated positive significant trend $\left(+0.14^{\circ} \mathrm{C}\right.$ year). In Arafat area mass tree plantation has taken place during the last couple of decades. Furthermore, Arafat has experienced no urbanization, as it is one of those Holy areas that are reserved for the purpose of Hajj. During the study period greenery in Arafat area has increased significantly since the plantation project was started in 1986. In contrast rapid urbanization, resulting in increase in energy use, road traffic, and change in land usage has led to temperature rise in most parts of the Makkah City including Waly Al-Ahd. This study shows how local factors, such as vegetation can affect local temperature trend. Arafat tree plantation project can be used as a good example to encourage more tree plantation in the Holy sites to cope with the increasing heat in the coming decades. Trees also provide shelter from the blazing sun, especially during Hajj season in Makkah, where temperature reaches as high as $50^{\circ} \mathrm{C}$ in summer months and probably will continue to rise in the future.
\end{abstract}

Keywords: temperature, temporal trend, Makkah, vegetation.

Introduction

Extreme temperature can affect plants, animals and human health. Many studies (e.g., Anderson and Bell, 2008; Bai et al., 2014) have linked temperature to health risk including increased risk of mortality at both extremely low and high temperatures. High temperature is the main reason of heat cramps, heat exhaustion and eventually heat stroke. It is reported that elderly, women, and individuals with chronic health problems, such as those with diabetes or cardiovascular disease are more vulnerable when exposed to high temperature (Analitis et al., 2008; Benmarhnia, et al., 2015). Long term variations in temperature can influence agriculture, energy use, transportation systems and more importantly human health. Extreme temperature events (heat waves) are projected to become more frequent and more intense in the future due to global warming (Hatfield and Prueger, 2015). According to Intergovernmental Panel on Climate Change (IPCC, 2016) the levels of greenhouse gases, such as carbon dioxide $\left(\mathrm{CO}_{2}\right)$, methane $\left(\mathrm{CH}_{4}\right)$ and nitrous oxide $\left(\mathrm{N}_{2} \mathrm{O}\right)$ are increasing in the atmosphere, which are considered the main greenhouse gases and one of the causes of global warming. These gases are emitted by the combustion of fossil fuels in cars, factories, and electricity production, the loss of forests that would otherwise store $\mathrm{CO}_{2}$, landfills and agriculture, fertilizers, gases used for refrigeration and industrial processes.

The effect of climate change is more evident in semi-arid and arid regions of the world, like Saudi Arabia which experiences extremely high 
temperature and water scarcity. Almazroui, et al., 2012a) investigated annual averaged air temperature in Saudi Arabia during 1978 2009 and reported a positive trend $0.60^{\circ} \mathrm{C} /$ decade. It was found that temperature trend varied both spatially throughout the country and temporally in different seasons (Almazroui et al., 2012b). Furthermore, Rehman and AlHadhrami (2011) analyzed temperature trend from 1970 to 2006 in Jeddah, Saudi Arabia and found that temperature had increased significantly. This increase trend of temperature i.e. the warming over the kingdom is confirmed by the work of Almazroui et al. (2014). Alghannam and Al-Qahtnai (2012) studied air temperature differences between rural and urban areas in Al-Hassa oasis in the eastern province of the Kingdom Saudi to investigate the effect of vegetation, especially date palms on local air temperature. Their results showed that the date palms had a cooling effect on air temperature and caused mean temperature to decrease by $4^{\circ} \mathrm{C}$ and maximum by $6.6^{\circ} \mathrm{C}$. Munir et al. (2013) and Munir (2015) investigated the effect of air temperature on air quality in Makkah and reported that air temperature had positive association with particulate matter i.e. as temperature increased it caused particulate matter levels to rise probably due to enhanced re-suspension of soil-and-road dust and formation of secondary aerosol. A temperature increase from 10 to $35^{\circ} \mathrm{C}$ resulted in $\mathrm{PM}_{10}$ concentration to rise by a factor of 4 in warm days during summer (Munir, 2015). Abdou (2014) analyzed temperature trends in Makkah from 1985 to 2013 using both linear regression and Theil-Sen analysis. Abdou (2014) found that the number of both hot days and nights had increased annually by 1.5966 and 1.832, respectively, however the number of cold nights had decreased annually by 0.4054 nights. Mean, minimum and maximum temperature demonstrated positive trends. Furthermore, the annual mean of daily mean, maximum and minimum temperature increased by $0.0398^{\circ} \mathrm{C}, 0.0552^{\circ} \mathrm{C}, 0.0398^{\circ} \mathrm{C}$ per year, respectively (Abdou, 2014).

Makkah is a densely populated city and according to the general authority for statistics of the Kingdom of Saudi Arabia (CDSI, 2016) its population is more than 8 millions. Makkah is considered the Holiest City in the Muslim World, and therefore millions of Muslims visit the city every year to perform Umrah and Hajj (Pilgrimage). Makkah is situated in a hot arid region, where mean temperature is $31.42^{\circ} \mathrm{C}$ and maximum temperature reaches over $55^{\circ} \mathrm{C}$ during the summer months (summer average is $36.11^{\circ} \mathrm{C}$ ) (Almazroui, 2012). Considering the importance of Makkah city, this study aims to determine the temperature trends in Makkah in recent one and a half decade, and analyze how local factors, especially vegetation affect temperature trend. The rest of the study is organized as follows. Next section presents the Methodology adopted for the study followed by 'Results and Discussion' Section, while 'Conclusion' are presented at the end of the paper.

\section{Methodology}

The main aim of this study is to analyze temperature trend and investigate the effect of local factors, especially vegetation on observed temperature trend in Makkah. To fulfil the aim, this study used a 15 years (2002 - 2016) hourly dataset recorded at two monitoring stations - Arafat and Waly Al-Ahd in Makkah (Fig. 1). A map of Arafat area (Fig. 2, bottom) and a photo of the monitoring station (Fig. 2, top) are provided to show the surrounding area more closely and to show that the monitoring station is not under a tree and is a true representative of the whole Arafat area. A summary of temperature data recorded in Arafat and Waly AL-Ahd (Leeth Road) areas is presented in Table 1 , which shows that in Makkah maximum temperature can reach as high as $55^{\circ} \mathrm{C}$ and average temperature is about $31.42^{\circ} \mathrm{C}$. It is interesting to note that all the 
variables used in Table 1 show higher values for Waly Al-Ahd, however standard deviation shows higher value in Arafat station.

Statistical analysis was performed to study the long term temperature trend during the last 15 years (2002 - 2016), this study employed TheilSen function (Carslaw and Ropkins, 2012). TheilSen approach is based on median and is robust (non-sensitive) to outliers and to non-normal probability distribution. Trends are determined not only for mean temperature but also for median and several percentiles like 5th percentile, 25th percentile, 75th percentile and 95 percentile. Trends are also determined for various seasons according to the definition of Carslaw and Ropkins (2012): winter (November, December, January); spring (February, March, April); summer (May, June, July); and Autumn (August, September, October)

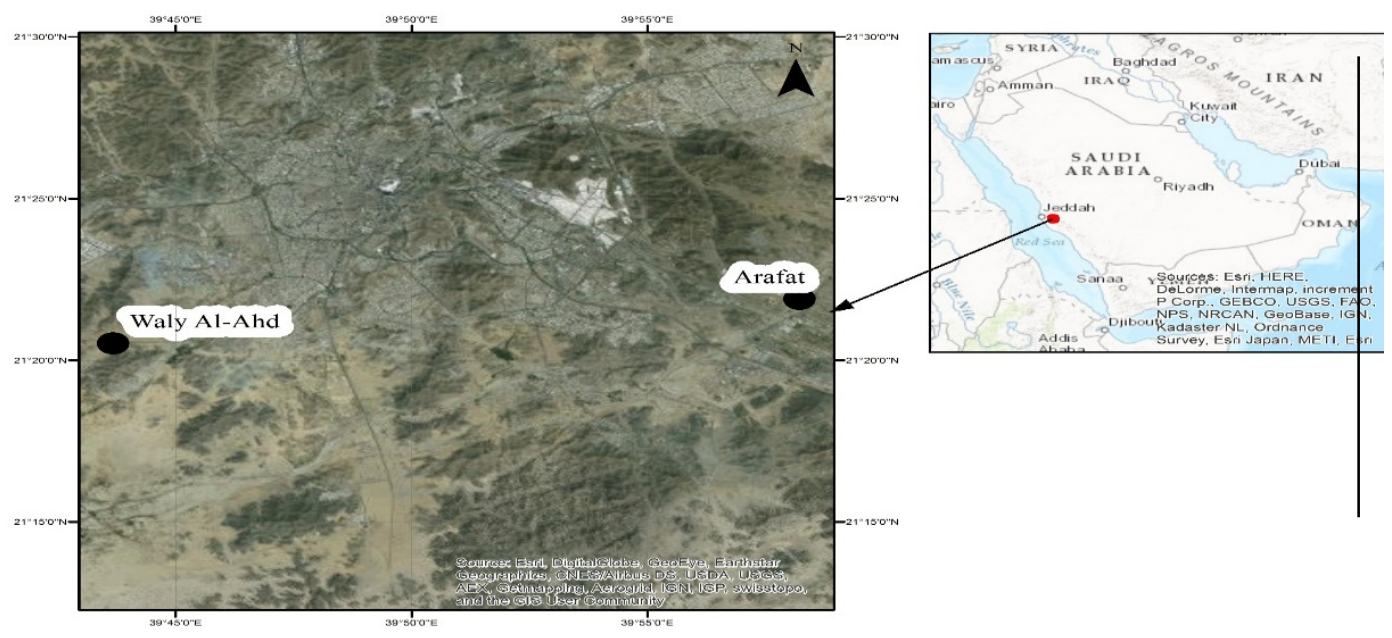

Fig. 1. Map of the meteorological monitoring sites in Makkah, Saudi Arabia.

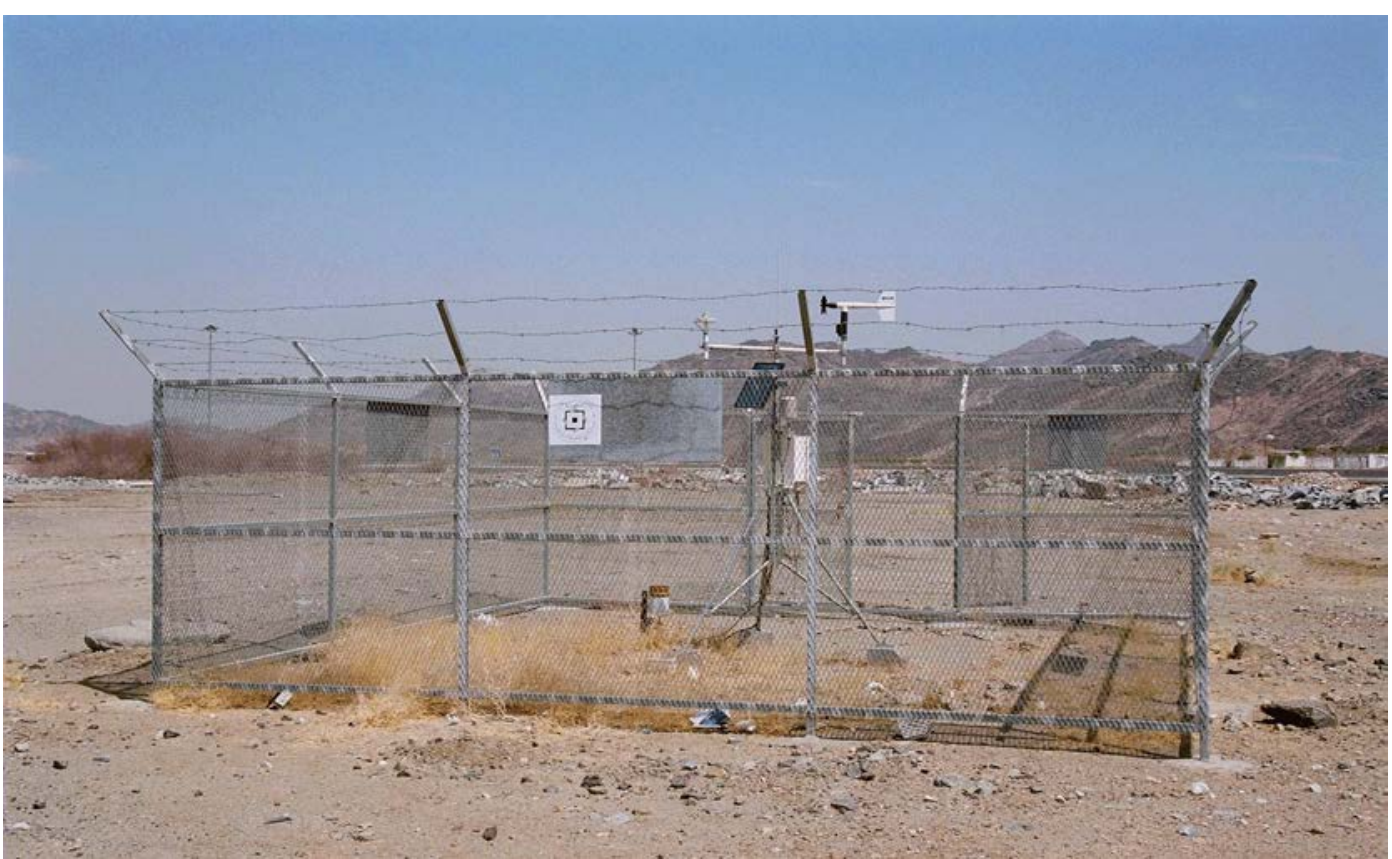




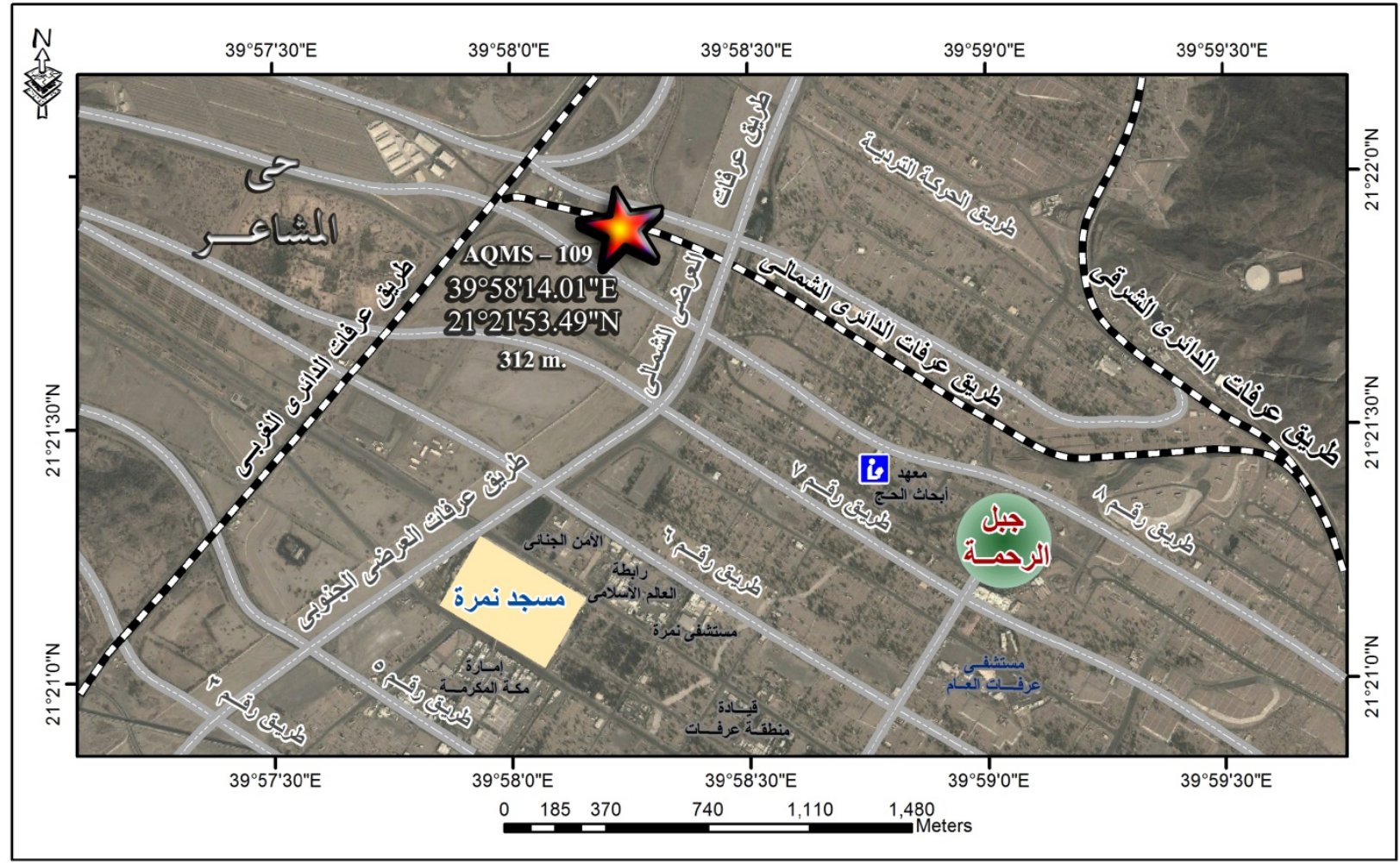

Fig. 2. Map of the Arafat area (bottom) and a photo of the monitoring station (top).

Table 1. Summary of temperature $\left({ }^{\circ} \mathrm{C}\right)$ data from Waly Al-Ahd and Arafat Sites in Makkah during 2002 - 2016.

\begin{tabular}{ccc}
\hline Metric & Temp_Arafat & Temp_Waly Al-Ahd \\
\hline Min & 9.81 & 10 \\
1st Q & 26.12 & 26.53 \\
Median & 30.76 & 31.05 \\
Mean & 30.93 & 30.96 \\
3rd Q & 35.10 & 35.20 \\
Max & 54.03 & 55.13 \\
SD & \pm 6.45 & \pm 5.89 \\
\hline
\end{tabular}

\section{Results and Discussion}

The mean results of TheilSen function are shown in Figures 3 \& 4 for Waly Al-Ahd and Arafat monitoring stations, respectively. Temperature trends at several percentiles are presented in Table 2. Figure 3 shows that temperature trend was positive (significant, $\mathrm{p}<0.05)$ at Waly Al-Ahd monitoring station $\left(0.14^{\circ} \mathrm{C}\right.$ /year). Furthermore, trends were estimated in various seasons. All four seasons demonstrated positive trends, however trends were significant in summer $\left(0.09^{\circ} \mathrm{C} /\right.$ year, $\mathrm{p}<$ $0.01)$ and winter $\left(0.11^{\circ} \mathrm{C} /\right.$ year, $\left.\mathrm{p}<0.05\right)$ only. Furthermore, trends were positive at various percentiles including 5th, 25th, median, 75th, and 95th percentiles. The positive trend in temperature levels is probably caused by both global and local factors. Scientists believe that the levels of greenhouse gases, such as carbon dioxide $\left(\mathrm{CO}_{2}\right)$, methane $\left(\mathrm{CH}_{4}\right)$ and nitrous oxide $\left(\mathrm{N}_{2} \mathrm{O}\right)$ are increasing in the atmosphere, which are the main cause of global warming. 
$\mathrm{CO}_{2}$ is responsible for the most warming and is mainly emitted by the combustion of fossil fuels in cars, factories and electricity production and the loss of forests that would otherwise store $\mathrm{CO}_{2} \cdot \mathrm{CH}_{4}$ is released from landfills and agriculture (especially from the digestive systems of grazing animals), whereas $\mathrm{N}_{2} \mathrm{O}$ is emitted from fertilizers, gases used for refrigeration and industrial processes. For more details on climate change see the various reports prepared by (IPCC, 2016). In addition to global factors, local factors also play an important role in positive temperature trend. Locally in Makkah rapid urbanization in Waly Al-Ahd area, which has led to increase in transportation, energy usage, and change in land usage, might have played a significant role in the observed temperature trend.
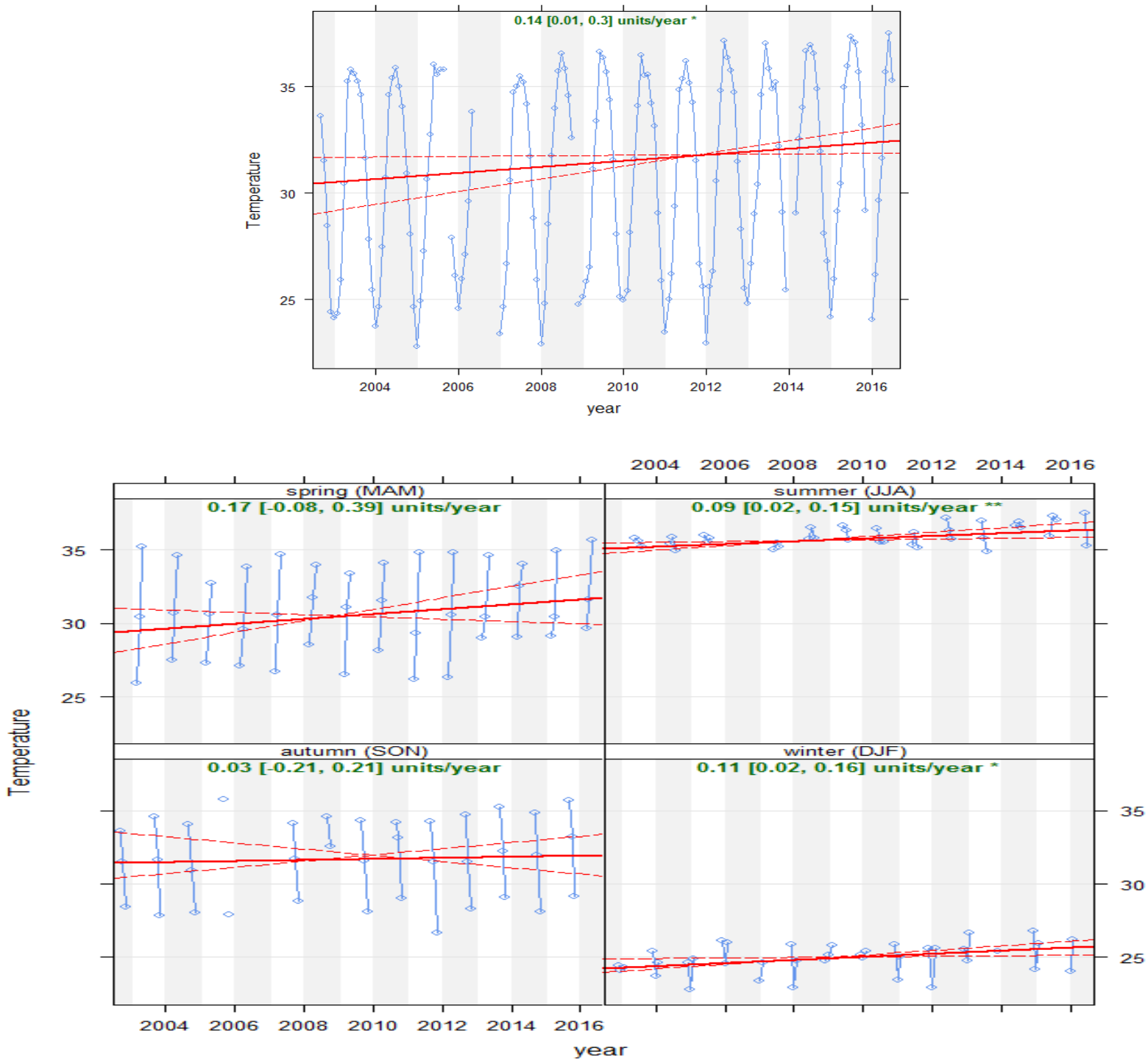

Fig. 3. Temperature trend during 2002 - 2016 (top) and during various seasons (bottom) in Waly Al-Ahd Makkah. The solid red line shows the trend estimate and the dashed red lines show the $95 \%$ confidence intervals for the trend based on resampling methods. The overall trend is shown at the top-left of each panel outside the brackets in units of degree Celsius per year and the $95 \%$ confidence intervals in the slope are given inside the brackets. The * or ** show that the trend is significant at $\mathrm{p}$-level $<0.05$ and $\mathrm{p}$-level $<0.01$, respectively. The blue line with squares shows the actual data. 
Table 2. Temporal trends $\left({ }^{\circ} \mathrm{C} / \mathrm{year}\right)$ in temperature levels at various percentiles from 2002 to 2016 in Arafat and Waly AlAhd, Makkah.

\begin{tabular}{|c|c|c|c|c|c|}
\hline Site & metric & lower & upper & slope & p. stars \\
\hline \multirow{6}{*}{ Arafat } & Mean & -0.20 & 0.10 & -0.05 & ns \\
\hline & $5^{\text {th }} \%$ ile & -0.23 & 0.10 & -0.08 & ns \\
\hline & $25^{\text {th }} \%$ ile & -0.20 & 0.08 & -0.06 & ns \\
\hline & $50^{\text {th }} \%$ ile & -0.22 & 0.09 & -0.06 & ns \\
\hline & $75^{\text {th }} \%$ ile & -0.22 & 0.13 & -0.04 & ns \\
\hline & $95^{\text {th }} \%$ ile & -0.19 & 0.16 & -0.01 & ns \\
\hline \multirow{6}{*}{ Waly Al-Ahd } & Mean & 0.01 & 0.30 & 0.14 & $*$ \\
\hline & $5^{\text {th }} \%$ ile & 0.01 & 0.33 & 0.16 & $*$ \\
\hline & $25^{\text {th }} \%$ ile & 0.03 & 0.31 & 0.16 & $*$ \\
\hline & $50^{\text {th }} \%$ ile & 0.01 & 0.31 & 0.15 & $*$ \\
\hline & $75^{\text {th }} \%$ ile & -0.02 & 0.29 & 0.13 & ns \\
\hline & $95^{\text {th }} \%$ ile & -0.03 & 0.29 & 0.12 & ns \\
\hline
\end{tabular}

Note: p.stars relate to how statistically significant the trend estimate is: $\mathrm{p}<0.001=* * *, \mathrm{p}<0.01=* *, \mathrm{p}<0.05=*$ and $\mathrm{p}<0.1=+$, ns $=$ nonsignificant.

Temperature showed negative trends in Arafat area (Figure 4 and Table 2). It is interesting to see that Arafat has demonstrated negative trends at all metrics (mean, median, 5th percentile, 25th percentile, 75th percentile and 95th percentile). Mean trend was $-0.02^{\circ} \mathrm{C}$ year during the whole study period. However, trend during the last 8 years (2009 to 2016) was even greater $\left(-0.1^{\circ} \mathrm{C} /\right.$ year $)$. Furthermore, when trend was analyzed during different seasons, only summer demonstrated negative trend ($0.02^{\circ} \mathrm{C} /$ year). This analysis shows that temperature trends vary from site to site, most probably due to micro-local characteristics and land use within Makkah. Arafat area is one of those Holy areas that has been reserved only for the Hajj season. Pilgrims spend only one day here known as the day of Arafah on the 9th of Zulhijjah (the 12th month of Islamic Calendar) and during the rest of the year no one lives or works here. During the study period greenery of the area has increased significantly. The Arafat plantation project was started in 1986. Initially several neem trees were planted, however since then the number of neem trees has increased significantly and have covered the whole Arafat area. The trees are used for their shade on the day of Arafah, when temperature in summer gets as high as $55^{\circ} \mathrm{C}$. The plantation project has probably played a vital role in the temperature negative trends in this area. 

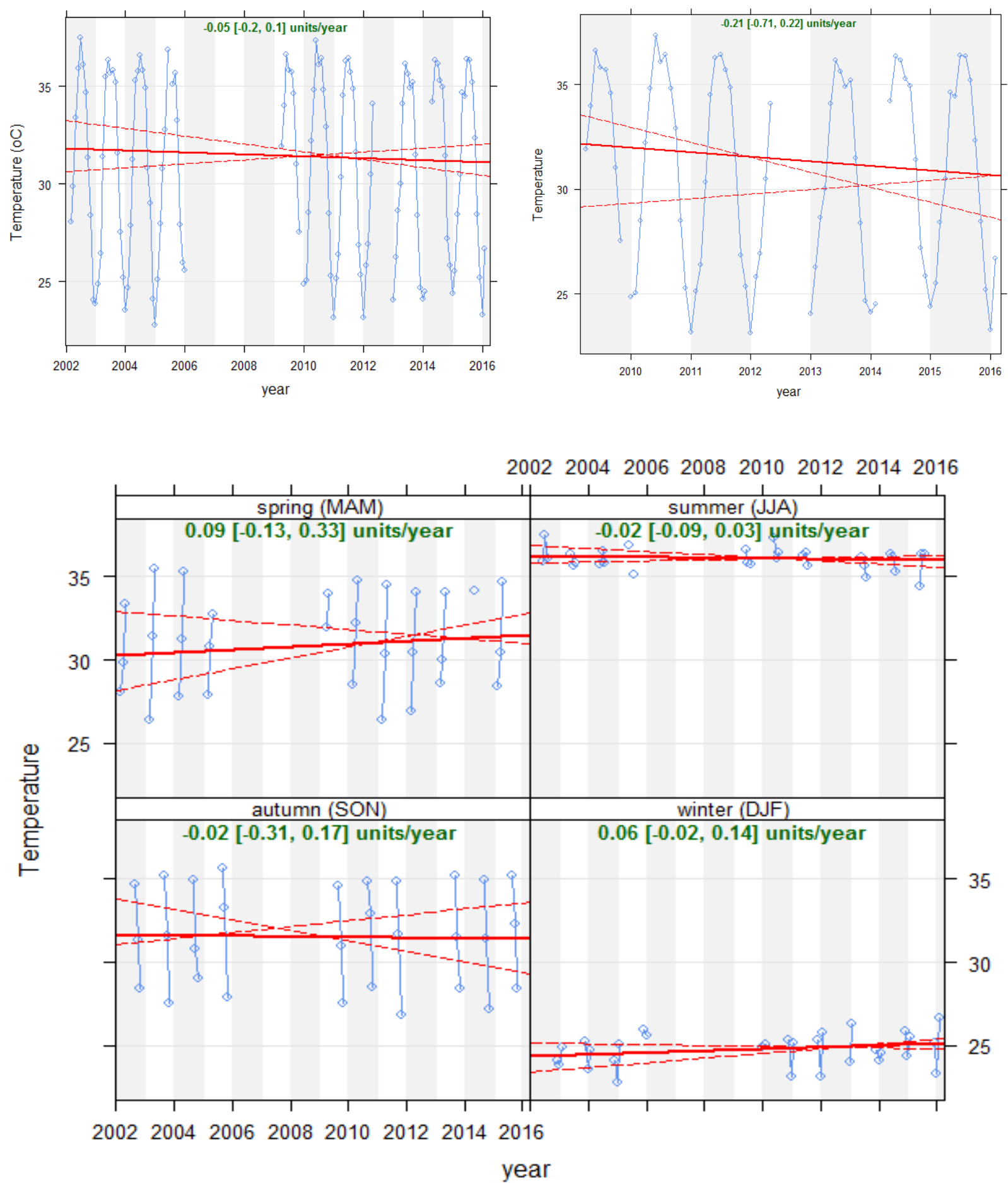

Fig. 4. Temperature trend during 2002 - 2016 (top), 2009 - 2016 (middle), and during various seasons (bottom) in Arafat Makkah. The solid red line shows the trend estimate and the dashed red lines show the $95 \%$ confidence intervals for the trend based on resampling methods. The overall trend is shown at the top-left of each panel outside the brackets in units of degree Celsius per year and the $95 \%$ confidence intervals in the slope are given inside the brackets. The * or ** show that the trend is significant at $\mathrm{p}$-level $<0.05$ and $\mathrm{p}$-level $<0.01$, respectively. If there are no $*$, this means the trend is not significant. The blue line with squares shows the actual data. 
Positive temperature trend in urban areas is one of the major problems in large urban areas throughout the world. However, in Saudi Arabia the increasing temperature could be more serious as maximum hourly temperature already gets as high as $55^{\circ} \mathrm{C}$. Various studies have shown that heat waves emanating from concrete roads and tall buildings keep urban areas hotter long after the sun has set as compared to rural areas which cool down rapidly. Urbanization tends to channel the net solar gains into sensible heat by increasing the air temperature, whereas the presence of trees and other vegetations in rural areas tends to channel it to latent heat by evapo-transpiration, which produces a desirable cooling effect and keep temperature moderate. Vegetation is considered to be one of the simplest and most effective ways to moderate climate, save energy used by running air conditions and fans, and clean air by reducing air pollution. In this study it is clear that vegetation in Arafat area has played a moderating effect on local temperature, therefore temperature has not increased during the study period and has rather decreased. Therefore, tree plantation needs to be seriously considered in arid climates, such as Makkah in Saudi Arabia to nullify the positive temperature trends due to local urbanization and regional and global warming due to climate change.

\section{Conclusions}

This study compares temperature trends at two monitoring stations in Makkah during 2002 2016. Temperature trends are analyzed both annually and in different seasons. In addition to mean, trends are also determined at median and 5th, 25th, 75th and 95th percentiles. It was found that in Waly Al-Ahd area temperature has increased, whereas in Arafat area temperature has not increased, it has rather decreased during the study period. Various potential reasons for the trends are discussed and it is believed that tree plantations project in Arafat area is probably having a moderating effect on local temperature. Further projects like this are encouraged to moderate temperature in Makkah and provide shelters for Pilgrims from the blazing sun while performing Hajj, especially in the summer season.

\section{References}

Alghannam, A.R.O. and Al-Qahtnai, M.R.A. (2012) Impact of vegetation cover on urban and rural areas of arid climates, Australian Journal of Agricultural Engineering, 3 (1): 1-5.

Abdou, A.E.A. (2014) Temperature trend on Makkah, Saudi Arabia, Atmospheric and Climate Sciences, 4: 457-481.

Almazroui, M. (2012) Temperature variability over Saudi Arabia during the period 1978-2010 and its association with global climate indices, Journal of King Abdulaziz University: Met Env Arid Land Agric Sci., 23 (1): 85-108. DOI: 10.4197/Met.23-1.6.

Almazroui, M., Islam, M.N., Athar, H., Jones, P.D. and Rahman, M.A. (2012a) Recent climate change in the Arabian Peninsula: annual rainfall and temperature analysis of Saudi Arabia for 1978-2009. International Journal of Climatology, 32: 953-966. DOI: 10.1002/joc.3 446.

Almazroui, M., Islam, M., Nazrul, Jones P.D., Athar, H. and Rahmana, M. Ashfaqur (2012b) Recent climate change in the Arabian Peninsula: Seasonal rainfall and temperature climatology of Saudi Arabia for 1979-2009, Atmospheric Research, 111: 29-45, DOI:10.1016/j.atmosres.2012.02.013.

Almazroui, M., Islam, M. N., Dambul, R. and Jones, P. D. (2014) Trends of temperature extremes in Saudi Arabia, International Journal of Climatology, 34: 808-826, DOI: 10.1002/joc.3722.

Analitis, A., Katsouyanni, K., Biggeri, A., Baccini, M., Forsberg, B., Bisanti, L., Kirch- mayer, U., Ballester, F., Cadum, E., Goodman, P.G., Hojs, A., Sunyer, J., Tiittanen, P. and Michelozzi, P. (2008) Effects of cold weather on mortality: results from 15 European cities within the PHEWE project, American Journal of Epidemiology, 168 (12): 1397-1408.

Anderson, G.B. and Bell, M.L. (2008) Extreme Temperature Effects: A Study of the Effects of Heat, Cold, and Heat Waves on Human Mortality in 107 U.S. Cities, Epidemiology, 19 (6): 269.

Bai, L., Ding, G., Gu, S., Bi, P., Su, B., Qin, D., Xu, G. and Liu, Q. (2014) The effects of summer temperature and heat waves on heat-related illness in a coastal city of China, 2011-2013, Environmental Research, 132: 212 219.

Benmarhnia, T., Deguen, S., Kaufman, J.S. and Smargiassi, A. (2015) Review article: vulnerability to heat-related mortality: a systematic review, meta-analysis, 
and meta-regression analysis. Epidemiology, 26 (6): 781793.

Carslaw, D.C. and Ropkins, K. (2012) Openair - an R package for air quality data analysis, Environmental Modelling and Software, 27-28: 52-61.

CDSI (2016) Central Department of Statistics and Information of Saudi Arabia, 2016. http://www.cdsi.gov.sa/en/3137 (Accessed 19/09/2016).

Hatfield, J.L. and Prueger, J.H. (2015) Temperature extremes: Effect on plant growth and development, Weather and Climate Extremes, 10 (A): 4-10.

IPCC (2016) Intergovernmental Panel on Climate Change: http://www.ipcc.ch/publications_and_data/publications_an d_data_reports.shtml (accessed 18/09/2016).
Munir, S., Habeebullah, T.M., Seroji, A.R., Morsy, E.A., Mohammed, A.M.F., Saud, W.A., Esawee, A.L. and Awad, A.H. (2013) Modelling particulate matter concentrations in Makkah, applying a statistical modelling approach, Aerosols and Air Quality Research, 13: 901910.

Munir, S. (2015) Modelling the non-linear association of particulate matter $\left(\mathrm{PM}_{10}\right)$ with meteorological parameters and other air pollutants-a case study in Makkah, Arab Journal of Geosciences, 9, 64, DOI: 10.1007/s12517-0152207-7.

Rehman, S. and Al-Hadhrami, L.M. (2011) Extreme Temperature Trends on the West Coast of Saudi Arabia, Atmospheric and Climate Sciences, 2: 351-361.

\section{تأثير زر اعة الأشجار على اعتدال درجة الحرارة في مشعر عرفات بمدينة مكة

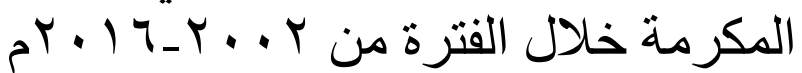

سيد منير وتركي محمد حبيب الله وعصام عبدالحليم مرسي وعاطف فتحي محمد

معهُ خادم الحرمين الثريفين لأبحاث الحج و العدرة، جامعة أم القرى، مكة المكرمة، المدلكة العربية السعودية 
المستخلص. تشير بعض الدر اسات الحالية إلى ارتفاع معدل درجة الحرارة على مستوى العالم. في حين

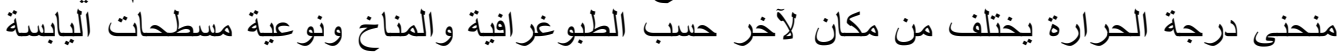

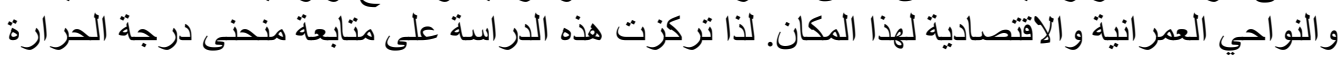

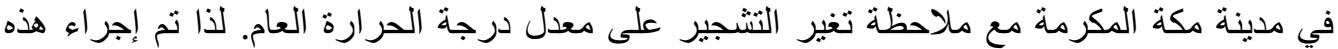

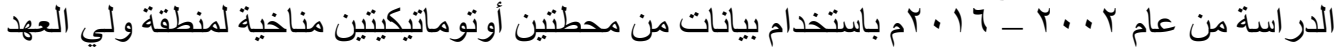

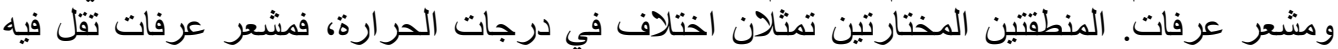

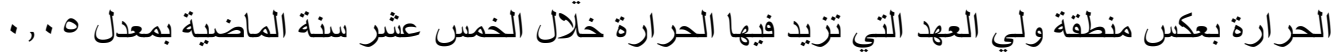

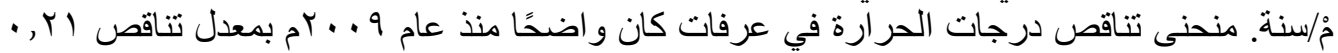

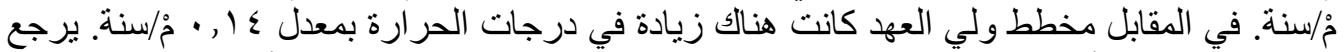

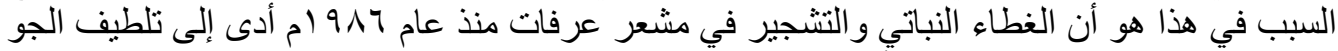

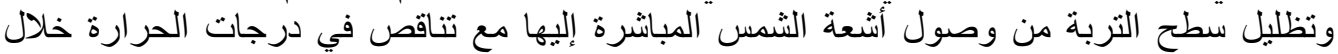

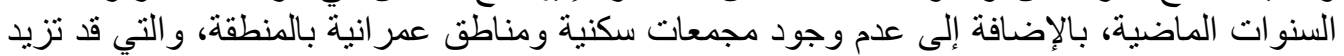

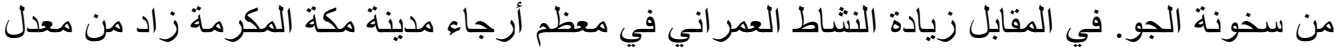

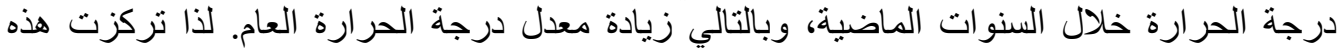

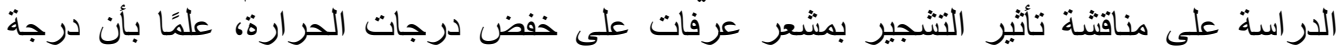

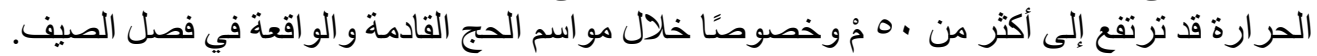
الكلمات الدالة: درجة الحرارة، المنحنى العام، مكة، التشجير. 